\title{
Structure, thermophysical properties and electrical conductivity of nanocomposites based on epoxy polymer and carbon tubes
}

\author{
V.V. Korskanov ${ }^{1}$ (ORCID 0000-0001-8204-5728), O.M. Fesenko ${ }^{1}$ (ORCID 0000-0002-9609-3568), \\ V.B. Dolgoshey² (ORCID 0000-0002-0147-3534) \\ 1 - Institute of physics of NAS of Ukraine, av. Nauki 46, Kyiv, 03028, Ukraine \\ Tel.: +380445251220 \\ E-mail:vk_dsc@ukr.net,fesenko@iop.kiev.ua \\ ${ }^{2}$ - National Technical University of Ukraine "Igor Sikorsky Kyiv Polytechnic Institute", av. Peremogy, Bldg. 37, \\ Kyiv, 03056, Ukraine \\ Tel.: +380931234802 \\ E-mail:vdolgoshey@ukr.net
}

Article info: received 16.02.2021, revised 10.03.2021, accepted 30.03.2021

Korskanov, V.V., Fesenko, O.M., Dolgoshey, V.B. (2021) Structure, thermophysical properties and electrical conductivity of nanocomposites based on epoxy polymer and carbon tubes 1(50), DOI: 10.26909/csl.1.2021.1

The aim of this work was to find the optimal conditions for the formation of nanocomposites, study their structure and properties and conditions for the formation of multicomponent materials based on epoxy polymers and carbon nanotubes with predetermined performance properties.

The basis for the formation of epoxy polymers was an epoxydian oligomer (EDO) based on bisphenol A. Polypox H354 was used as a hardener for EDO.

Carbon nanotubes (CNT) were used as a nanofiller for the preparation of nanocomposites.

The research methods were a diffractometer for measuring the intensity of X-ray scattering in the region of small angles and a differential scanning calorimeter for obtaining heating thermograms.

The electrical conductivity of the samples at a temperature of $293 \mathrm{~K}$ was measured at direct current according to the two-electrode scheme.

In this work the structure, thermophysical properties and electrical conductivity of nanocomposites based epoxy polymers and carbon nanotubes have been studied. It was found that at low CNT content the formation of nanocomposites occurs by the mechanism of epoxy network growth, which is accompanied by the displacement of CNT particles to the periphery of the epoxy matrix. This process is accompanied by an increase in the scattering intensity of the SAXS, a rapid increase in the glass transition temperature and the degree of crosslinking of the epoxy polymer. When the critical concentration is reached, CNT particles form a continuous cluster, which leads to occurrence percolation threshold, reducing the glass transition temperature, expanding the glass transition range, occurrence of pores and reducing the degree of completion of the crosslinking reaction in nanocomposites relative to the epoxy polymer. It is established that the improvement of nanocomposite properties and the occurrence of the percolation threshold is due to the maximum specific energy of ER-CNT interaction and is achieved at a critical mass concentration of nanofiller from $0,1 \%$ to $0,4 \%$.

Key words: carbon nanotubes, epoxy resin, structure, thermophysical properties, electrical conductivity.

\section{Структура, теплофізичні властивості та електропровідність нанокомпозитів на основі епоксидного полімеру та карбонанотрубок}

\author{
В.В. Корсканов ${ }^{1}$, О.М. Фесенко ${ }^{1}$ В.Б. Долгошей ${ }^{2}$ \\ 1 - Інститут фізики НАН Украӥни, Київ, Україна \\ 2 - Наиіональний технічний університет Украйни "Київський політехнічний інститут імені Ігоря Сікорського", \\ Київ, Україна
}


Метою даної роботи було знайти оптимальні умови утворення нанокомпозитів, вивчити їх структуру та властивості та умови утворення багатокомпонентних матеріалів на основі епоксидних полімерів та вуглецевих нанотрубок із заданими експлуатаційними властивостями.

Основою для утворення епоксидних полімерів був епоксидний олігомер на основі бісфенолу А. Поліпокс Н354, що використовувався як затверджувач.

Вуглецеві нанотрубки використовувались як нанонаповнювач для одержання нанокомпозитів.

Методами дослідження були дифрактометрія для вимірювання інтенсивності розсіювання рентгенівських променів в області малих кутів та диференціальний скануючий калориметр для отримання термограм нагрівання.

Електропровідність зразків при температурі 293 К вимірювали постійним струмом за двоелектродною схемою.

У цій роботі досліджені структура, теплофізичні властивості та електропровідність нанокомпозитів на основі епоксидних полімерів та вуглецевих нанотрубок. Встановлено, що при низькому вмісті вуглецевих нанотрубок утворення нанокомпозитів відбувається за механізмом зростання епоксидної мережі, що супроводжується виштовхуванням частинок вуглецевих нанотрубок на периферію епоксидної матриці. Цей процес супроводжується збільшенням інтенсивності розсіювання SAXS, швидким підвищенням температури склування і ступенем зшивання епоксидного полімеру. При досягненні критичної концентрації частинки вуглецевих нанотрубок утворюють суцільний кластер, що призводить до появи порогу перколяції, зниження температури склування, розширення діапазону склування, появи пор і зменшення ступеня завершення реакції зшивання в нанокомпозитах відносно епоксиднго полімеру. Встановлено, що поліпшення властивостей нанокомпозитів та виникнення порогу перколяції зумовлені максимальною питомою енергією взаємодії ER-CNT та досягаються при критичній масовій концентрації нанонаповнювача від 0,1% до 0,4%.

\section{Вступ}

Вуглецеві нанотрубки (ВНТ), завдяки своїм високим механічним властивостям, унікальним геометричним параметрам (значне відношення довжини до діаметра), високій питомій поверхні, тепло- та електропровідності, $є$ ефективними наповнювачами для отримання полімерних нанокомпозитів (НК) із заданими високими експлуатаційними властивостями $[1,2]$. У XXI столітті такі НК отримали широке застосування в галузі біомедичної науки [3], як анодний матеріал для натрієвих та літій-іонних батарей [4], у високопродуктивних суперконденсаторах [5], провідних аерокосмічних клеях [6], для просування електроніки наступного покоління [7] тощо.

Епоксидні полімери (ЕП), які характеризуються високою термостійкістю, значною адгезією до різних матеріалів (металів, скла, кераміки тощо), широко використовуються як клеї, антикорозійні покриття, герметики, та є перспективними як полімерні матриці для приготування інноваційних НК $[8,9]$.

Саме тому нанокомпозити на основі ЕП та УНТ, які поєднують корисні властивості кожного 3 компонентів, представляють великий інтерес для дослідників [10 - 15].

Метою даної роботи було відпрацювання оптимальних умов формування НК, вивчення їх структури, властивостей та умов формування багатокомпонентних матеріалів на основі ЕП та ВНТ з наперед заданими експлуатаційними властивостями.

\section{Матеріали та методи дослідження}

Основою для формування НК слугував епоксидіановий олігомер (ЕДО) на основі бісфенолу А,

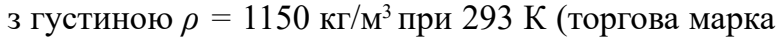
DER 321 від DOW Chemical) [16]. Як отверджувач для ЕДО був використаний Polypox H354 (виробник UPPC (ФРН)) [17].

В якості нанонаповнювача для приготування НК використовували ВНТ з густиною 2100 кг/м², зовнішнім діаметром 20 нм та питомою поверхнею $196000 \mathrm{м}^{2} /$ кг [18].

Вихідний епоксидний полімер отримували змішуванням ЕДО з Рolypox Н354 у співвідношенні 100:52 вагових частин, відповідно. Суміш витримували 24 години при кімнатній температурі на протязі згідно технологічним вимогам виробника (ЕП-I). Подальше термічне зшивання проводили на протязі 4-х годин при температурі 473 К (ЕП-II).

Формування НК проводили суміщенням розрахованої кількості УНТ з ЕДО, активного перемішування та наступною обробкою ультразвуком при частоті 44 МГц на протязі однієї години. Після додавання Polypox H354 та перемішування зразки ЕП-І+ВНТ формували на тефлоновій підложці при температурі 293 К на протязі 24 годин. Зразки ЕПII+ВКНТ були отримані високотемпературним доотвердженням зразків серії ЕП-І+ВНТ при температурі 473 К на протязі 4 годин.

Схематично процес приготування НК представлено на рис. 1. 


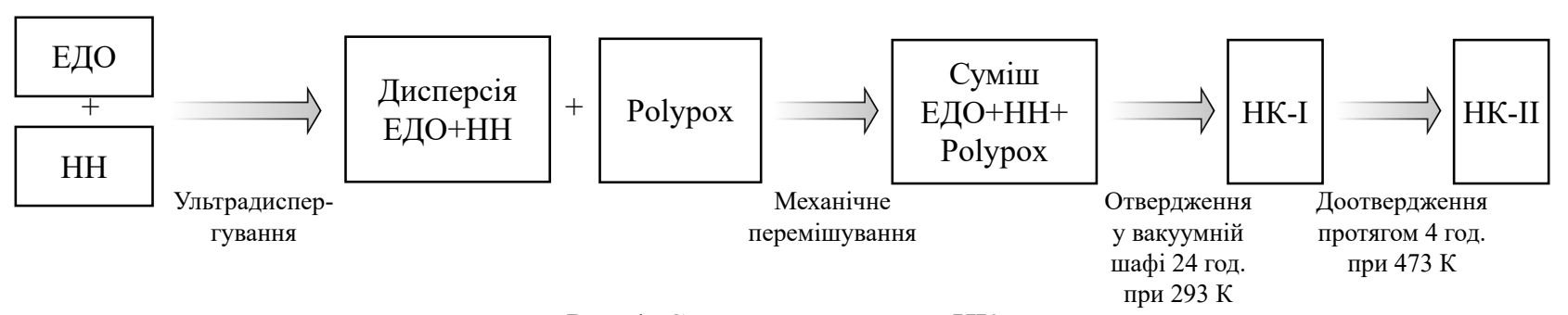

Рис. 1. Схема приготування НК

Таким чином були отримані зразки ЕП та серії НК 3 масовим вмістом ВНТ від 0,05 до $1,0 \%$ та досліджені їх властивості.

Криві малогокутового розсіювання рентгенівських променів (МКРП) були отримані у вакуумній камері типу Краткі, за допомогою дифрактометра КРМ-1. Вимірювання проводили 3 використанням мідного анода, монохромованого нікелевим фільтром в режимі багатоступеневого сканування в діапазоні розсіювання $2 \theta$ від 0,0124 до 12,0 . Довжина хвилі рентгенівського випромінювання становить $\lambda$ $=0,154$ нм [18].

Густину $\rho$ зразків визначали методом гідростатичного зважування у еталонному ізооктані.

Термограми ДСК були отримані в температурному інтервалі 253 - 443 К при швидкості нагрівання $5 \mathrm{~K} /$ хв. за допомогою калориметра Q2000 (ТА Instrument (USA).

Електропровідність зразків при температурі $293 \pm 2$ К вимірювали на постійному струмі за двохелектродною схемою, описаною в [19].

\section{Результати та їх обговорення}

На рис. 2 показані МКРП криві для ЕП-ІІ, ВНТ, EП-II + 0,1 \% ВНТ та ЕП-II + 1,0 \% ВНT.

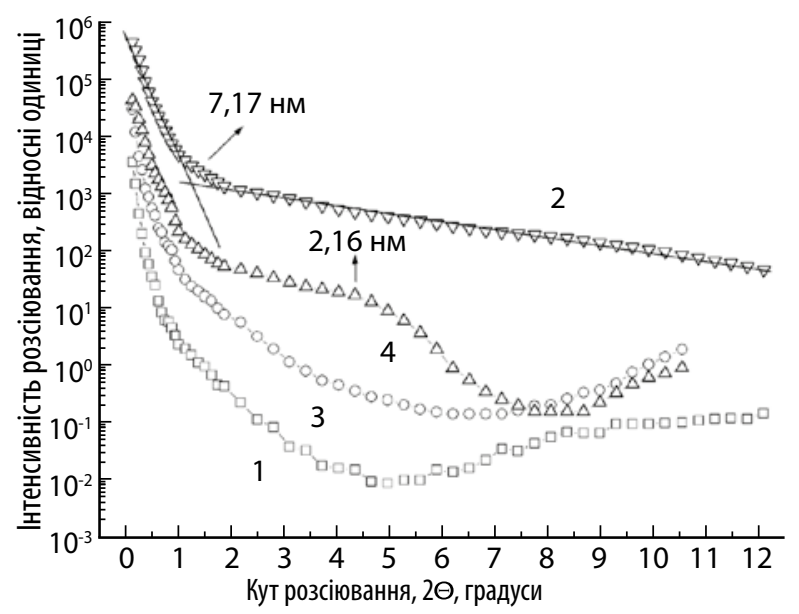

Рис. 2. Криві МКРП для ЕП-ІІ (1), ВНТ (2), ЕП-II + 0,1 \% ВНТ (3) та ЕП-II + 1,0 \% ВНТ (4)
Крива МКРП чистого ЕР-ІІ (див. крива 1 на рис. 2) характеризується низьким рівнем розсіювання рентгенівських променів та формою, типовою для аморфних систем. На відміну від цього, крива розсіювання рентгенівських променів від ВНТ має високий рівень розсіювання і відповідає моделі «пухкого клубка» із середнім діаметром близько 7,17 нм (крива 2 на рис. 2) [22]. Для зразка ЕП-II + 0,1 \% ВНТ крива МКРП також характерна для аморфних систем, але інтенсивність розсіювання вища, ніж для вихідного ЕП-ІІ. На кривій розсіювання для ЕП-ІІ + 1,0 \% ВНТ ми бачимо плато 3 характерним середнім розміром близько 2,16 нм (крива 4 на рис. 2). На наш погляд, це плато разом з високим рівнем розсіювання відповідає порам у структурі зразка.

Отримані температурні залежності теплоємності зразків (рис. 3) є типовими для НК на основі ЕП [20].

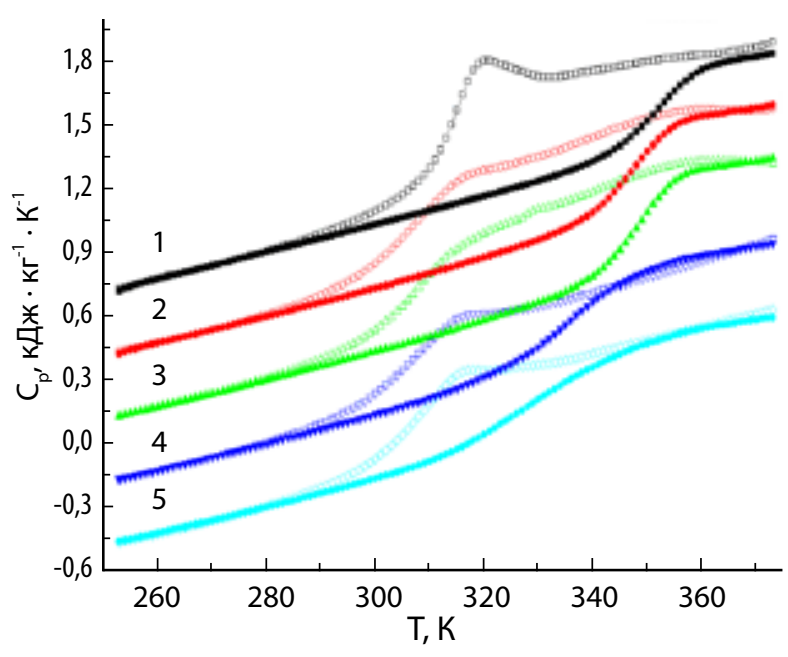

Рис. 3. Термограми ДСК досліджених зразків. Світлі позначення - зразки серії ЕП-I, темні - зразки серії ЕП-II.

Масовий вміст ВНТ: $1-0 \%, 2-0,05 \%$ (термограми зсунуті по осі ординат на - 0,4 кДж/(кг×К)), $3-0,1 \%$ (термограми зсунуті по осі ординат на 0,6 кДж/(кг×К)), 4 - 0,5 \% (термограми зсунуті по осі ординат на - 0,9 кДж/(кг×К)), 5 - 1,0 \% (термограми зсунуті по осі ординат на - 1,2 кДж/(кг×К)) 
На термограмі ДСК для ЕП-І чітко вирізняється стрибок теплоємності при температурі склування $T_{g}$, на який накладається ендотермічний релаксаційний ефект в області температур 317 - 334 К (рис. 3). У термообробленому зразку (ЕП-II) ендотермічний ефект зникає, а $T_{g}$ значно підвищується. На термограмах НК зразків серії ЕП-І з ростом вмісту БКНТ ендотермічний ефект стає значно меншим, а стрибок теплоємності при склуванні $\Delta C_{p}$ зменшуються. У зразках серії ЕП-ІІ, як $T_{g}$, так і $\Delta C_{p}$ з ростом $w$ проявляють тенденцію до зниження.

3 рис. 3. видно, що при термообробці нанокомпозитів та зі зміною складу характеристики процесів склування еволюціонують. Це значить, що змінюються і параметри структурної кооперативної реорганізації НК.

Усереднений об'єм областей кооперативності структурної реорганізації при склуванні розраховували за формулою [21]

$$
v_{\text {кооп }}=k \cdot T_{g}^{2} /\left(\Delta C_{p} \cdot \rho \cdot\left(\Delta T_{g} / 2\right)^{2}\right),
$$

де $k=1,38 \times 10^{-23}$ Дж/К - постійна Больцмана, $T g$ - температура склування, $\Delta C_{p}-$ стрибок теплоємності при склуванні, $\Delta T g$ - температурний інтервал процесу склування.

У першому наближенні вважали, що області кооперативності структурної перебудови є сферичними, їх середній діаметр визначали за формулою

$$
d=\left(3 v_{\text {кооп }} / 4 \pi\right)^{1 / 3} \text {. }
$$

Формально за розмір областей структурних перебудов при склуванні можна вважати характеристику рухливості їі складових, тобто, чим вища рухливість складових речовини - тим менший розмір кооперативності. I навпаки чим менша рухливість складових речовини - тим менша їх індивідуальність.

Процес еволюції термограм під час формування епоксидного полімеру ЕП наведено на рис. 4.

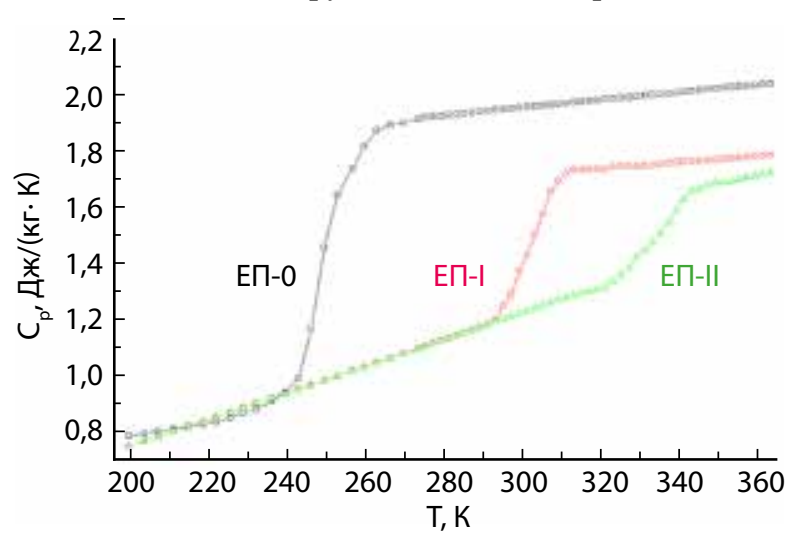

Рис. 4. Еволюція термограм ДСК при формуванні епоксидного полімеру ЕП
Отримане значення $T_{g}=305,7 \mathrm{~K}$ для ЕП-І значно перевищує відповідну величину для вихідного незшитого ЕП $\left(T_{g 0}=242,0 \mathrm{~K}\right)$, а стрибок теплоємності $\Delta C_{p}=0,547$ кДж/(кг $\left.\times \mathrm{K}\right)-$ значно менший $\Delta C_{p 0}=0,951$ кДж/(кг $\left.\times \mathrm{K}\right)$ - для ЕП (рис. 3). Для зразка, що зазнав термообробки (ЕП-ІІ), ці величини складають $T_{g}=348,0$ та $\Delta C_{p}=0,382$ кДж/(кг $\left.\times К\right)$, відповідно.

Ступінь завершеності реакції зшивання $\alpha$ епоксидного полімеру оцінювали за рівнянням Ді Бенедетто, що раніше засвідчило свою придатність для багатьох сітчастих полімерних систем, в тому числі і полімерних сіток на епоксидній основі [22]

$$
\alpha=\left[\frac{\Delta C_{p}}{\Delta C_{p 0}} \cdot \frac{T_{g \infty}-T_{g}}{T_{g}-T_{g 0}}+1\right]^{-1}
$$

де $\mathrm{T}_{g 0}, \Delta C_{p 0}$ - температура склування та стрибок теплоємності при склуванні неотвердженого ЕП, $\mathrm{T}_{g}, \Delta C_{p}-$ відповідні значення для досліджуваного зразка, $\mathrm{T}_{g \infty}$ - температура склування ЕП після термічного доотвердження.

Подальше обговорення отриманих результатів будемо проводити шляхом аналізу концентраційних залежностей теплофізичних властивостей за результатами таблиці 1.

Підвищення температури склування зразків $T_{g}$ серії ЕП-І разом з відповідним розширенням температурного інтервалу склування $\Delta T_{g}$ і значним зменшенням $\Delta C_{p}$ при збільшенні вмісту ВНТ до $w=0,1 \%$ свідчать про те, що в даній області складів ВНТ виступає як армуючий наповнювач щодо ЕП і приводить до збільшення гетерогенності НК. При подальшому підвищенні $w$ значення $T_{g}$ i $\Delta T_{g}$, проходять через максимум при $w_{н}=0,1 \%$ i залишаються приблизно однаковими при вищих $w_{н}$. На нашу думку, при $w>0,1 \%$ термодинамічний стан ЕП-І залишається сталим, а зменшення $\Delta C_{p}$ відбувається за рахунок зростання кількості контактів полімер-ВТН внаслідок підвищення валової питомої поверхні ВНТ.

Для зразків серії ЕП-ІІ температура склування у всьому інтервалі складів знижується з ростом $w$. Це свідчить про те, що у нанокомпозитах ВНТ утворюють стеричні перешкоди для формування полімерної сітки, які діють на структуру НК подібно до пластифікатора. Інтервал склування $\Delta T_{g}$, проходячи через мінімум при $w=0,1 \%$, залишається приблизно сталим. Значення стрибка теплоємності $\Delta C_{p}$ зростають при вмісті ВНТ $w<0,1 \%$, проходять через свій максимум при $w=0,1 \%$ і тяжіють до зменшення при $w>0,1 \%$.

Це призводить до того, що ступінь зшивання НК в цій області композиції зростає із збільшенням 
Таблиця 1.

Теплофізичні характеристики досліджених зразків

\begin{tabular}{|c|c|c|c|c|c|c|c|c|}
\hline № & Зразок & $T_{g}, \mathrm{~K}$ & $\Delta T_{g}, \mathrm{~K}$ & $\begin{array}{c}\Delta C_{p}, \\
\text { Дж/(кг×K) }\end{array}$ & $\begin{array}{c}\rho, \\
\kappa \Gamma / \mathrm{M}^{3}\end{array}$ & $v_{{ }_{\text {коon }},}{ } M^{3}$ & $d, H M$ & $a$ \\
\hline 1 & ЕП-0 & 242,0 & 25,1 & 0,951 & 1111,0 & 48,5 & 2,26 & 0,000 \\
\hline 2 & ЕП-I & 305,7 & 39,4 & 0,547 & 1166,0 & 52,1 & 2,32 & 0,724 \\
\hline 3 & ЕП-I+0,05 \%ВНТ & 306,6 & 45,2 & 0,530 & 1166,5 & 41,1 & 2,14 & 0,737 \\
\hline 4 & ЕП-I+0,08 \%ВНТ & 307,5 & 47,0 & 0,445 & 1167,0 & 45,5 & 2,21 & 0,776 \\
\hline 5 & ЕП-I+0,1 \%ВНТ & 309,3 & 48,6 & 0,408 & 1167,2 & 47,0 & 2,24 & 0,802 \\
\hline 6 & $\mathrm{E \Pi -I+0,2 \% BНТ}$ & 308,5 & 39,0 & 0,371 & 1168,0 & 79,7 & 2,67 & 0,812 \\
\hline 7 & ЕП-I+0,3\%ВНТ & 308,8 & 39,6 & 0,358 & 1169,5 & 94,0 & 2,82 & 0,819 \\
\hline 8 & $\mathrm{E \Pi -I+0,4 \% BНТ}$ & 308,6 & 39,2 & 0,305 & 1170,5 & 95,8 & 2,84 & 0,840 \\
\hline 9 & $\mathrm{E \Pi -I+0,5 \% ВНТ}$ & 308,7 & 39,4 & 0,291 & 1170,0 & 99,5 & 2,87 & 0,847 \\
\hline 10 & $\mathrm{E \Pi -I+1,0 \% BНТ}$ & 308,7 & 39,4 & 0,263 & 1168,0 & 110,3 & 2,97 & 0,912 \\
\hline 11 & ЕП-II & 348,0 & 26,2 & 0,382 & 1167,0 & 218,4 & 3,74 & 1,000 \\
\hline 12 & ЕП-II $+0,05 \%$ ВНТ & 346,5 & 25,3 & 0,454 & 1167,5 & 195,3 & 3,60 & 0,993 \\
\hline 13 & ЕП-II+0,08 \%ВНТ & 346,2 & 25,4 & 0,510 & 1168,0 & 172,1 & 3,45 & 0,991 \\
\hline 14 & ЕП-II+0,1 \%ВНТ & 345,5 & 25,3 & 0,530 & 1168,0 & 166,3 & 3,41 & 0,987 \\
\hline 15 & ЕП-II+0,2\%BНТ & 344,5 & 27,5 & 0,424 & 1169,0 & 174,8 & 3,47 & 0,985 \\
\hline 16 & ЕП-II+0,3 \%ВНТ & 342,0 & 30,2 & 0,420 & 1170,0 & 144,0 & 3,25 & 0,974 \\
\hline 17 & ЕП-II+0,4\%BНТ & 338,1 & 36,4 & 0,414 & 1171,0 & 98,2 & 2,86 & 0,957 \\
\hline 18 & ЕП-II+0,5 \%ВНТ & 336,0 & 40,4 & 0,410 & 1172,0 & 79,5 & 2,67 & 0,948 \\
\hline 19 & ЕП-II+1,0 \%ВНТ & 333,2 & 48,3 & 0,339 & 1168,2 & 48,0 & 2,55 & 0,945 \\
\hline
\end{tabular}

вмісту ВНТ (таблиця 1), тобто нанонаповнювач діє як ініціатор зшивання для нанокомпозитів. Це призводить до того, що ступінь зшивання НК $\alpha$ в цій області композиції зростає зі збільшенням вмісту ВНТ, тобто нанонаповнювач виступає ініціатором зшивання нанокомпозитів. Очевидно, що це результат ультразвукової дисперсії ЕДО з ВНТ на початковій стадії утворення нанокомпозитів (рис. 1).

При подальшому збільшенні $w$ значення $T_{g}$ i $\Delta T_{g}$ проходять через максимум при $w=0,1-0,2 \%$ і залишаються приблизно однаковими при вищому $w$. На наш погляд, при $w=0,1-0,2 \%$ термодинамічний стан ЕП-І залишається постійним, а зменшення $\Delta C_{p}$ відбувається за рахунок збільшення кількості контактів полімер-нанонаповнювач за рахунок збільшення загальної питомої поверхні площі ВНТ.
Обговорення результатів впливу термічного доотведнення на теплофізичні властивості НК проведемо $з$ аналізу складових рівняння (3). Різниця температур $\left(T_{g}-T_{g 0}\right)$ формально відображає загальний ефект зшивання НК. Нижчі значення цієї різниці у ЕП-І по відношенню до ЕП-ІІ свідчить про неповне зшивання компонентів у них. Зменшення значень $\left(T_{g}-T_{g 0}\right)$ у ЕП-ІІ зі збільшенням $w$ свідчить про вплив ВНТ як стеричних перешкод для утворення сітки зв'язків навіть у цілком сформованому НК.

Концентраційна залежність ступеня зшивання та розмірів кооперативності структурних перебудов приведена на рис. 5.

Як видно з рис. 5 величини $d$ та $\alpha$ цілком корелюють 3 приведеними вище висновками. Ці уявлення цілком підтверджуються наявністю порога перколя- 
ції електропровідності при $w=0,1-0,2 \%$ (рис. 6). Очевидно, що вищезазначена поведінка властивостей НК у першу чергу обумовлена максимальною енергією термодинамічної взаємодії у цій області складів [23].

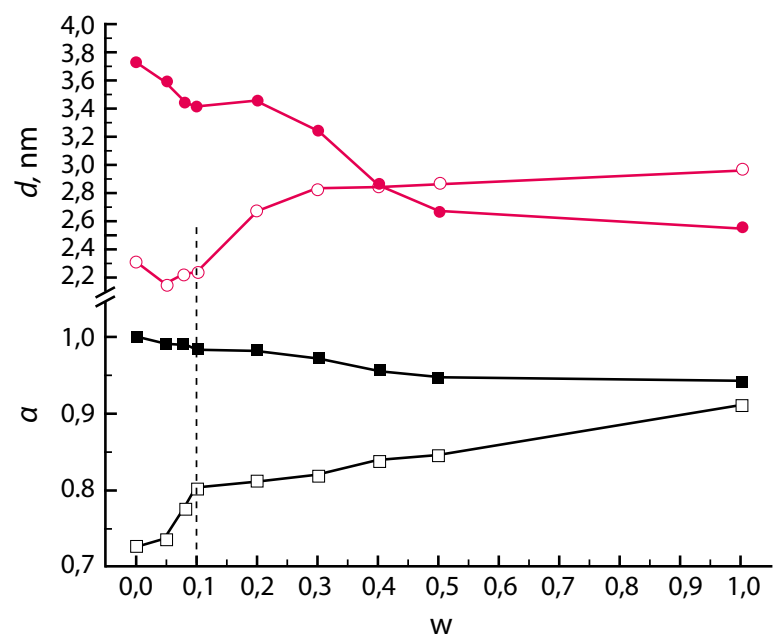

Рис. 5. Концентраційна залежність ступеня зшивання та розмірів кооперативності структурних перебудов

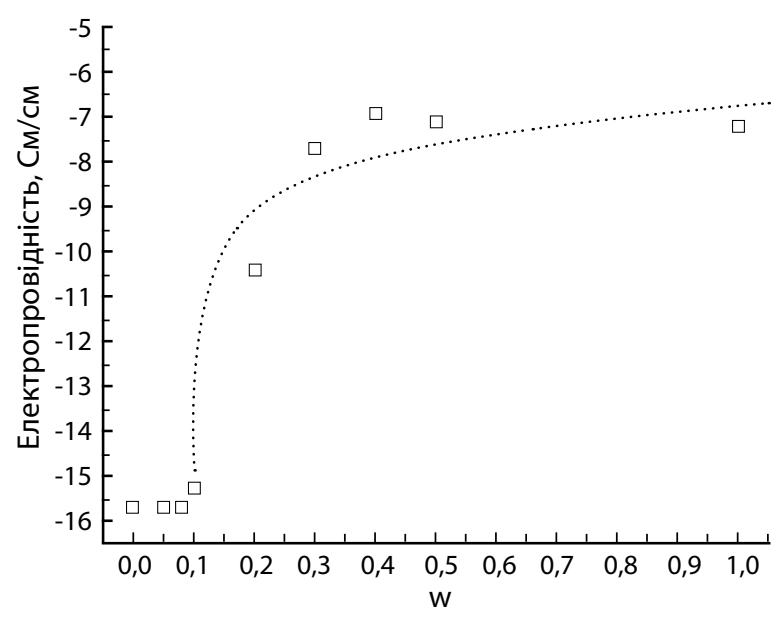

Рис. 6. Концентраційна залежність електропровідності досліджених НК

\section{Висновки}

Виявлено, що при малому вмісті УНТ формування нанокомпозитів відбувається по механізму росту епоксидної сітки, що супроводжується витісненням частинок УНТ на периферію епоксидної матриці. Цей процес супроводжується збільшенням інтенсивності розсіювання МКРП, швидким ростом температури склування та ступеня зшивки епоксидного полімеру. При досягненні критичної концентрації, частинки УНТ створюють неперервний кластер, що приводить до виникнення порогу перколяції електропровідності, зменшення температури склування, розширення температурного інтервалу склування, виникнення пор та зменшення ступеня завершеності реакції зшивання у нанокомпозитах по відношенню до епоксидного полімеру. Встановлено, що покращення властивостей нанокомпозитів та виникнення порогу перколяції обумовлено максимальною питомою енергією взаємодії ЕП-УНТ і досягається при критичній масовій концентрації нанонаповнювача від $0,1 \%$ до $0,4 \%$.

Роботу проведено в рамках НДДКР № 0121U1 00695.

\section{References}

1. Kumar, S.D., Alagarsamy, S.V., Chanakyan, C., Meignanamoorthy, M., Sakthivelu, S. Processing and properties of carbon nanotube reinforced composites: A review. Materialstoday: Processing. 2020. - 27. - P. 1152 - 1156. https://doi.org/10.1016/ j.matpr.2020.02.006

2. Pantano, A., Modica, G., Cappello, F. Multiwalled carbon nanotube reinforced polymer composites. Materials Science and Engineering: A. - 2008. 486 (1-2). - P. 222 - 227. https://doi.org/10.1016/j. msea.2007.08.078

3. Anzar, N., Hasan, R., Tyagi, M., Yadav, N., Narang, $J$. Carbon nanotube - A review on Synthesis, Properties and plethora of applications in the field of biomedical science. Sensors International. - 2020. - 1. https://doi. org/10.1016/j.sintl.2020.100003

4. Zhong, S., Liu, H., Wei, D., Hu, J., Zhang, H., Hou, H., Peng, M., Zhang, G., Duan, H. Long-aspect-ratio $\mathrm{N}$-rich carbon nanotubes as anode material for sodium and lithium ion batteries. Chemical Engineering Journal. - 2020. - 395. https://doi.org/10.1016/j.cej. 2020.125054

5. Liu, R., Sun, Sh., Zhong, R., Zhang, H., Wu, X. Nitrogen-doped microporous carbon coated on carbon nanotubes for high performance supercapacitors. Microporous and Mesoporous Materials. - 2020. - 305. https://doi.org/10.1016/j.micromeso.2020.110300

6. Jakubine, M.B., Ashrafi, B., Zhang, Yu., MartinezRubi, Y., Ch, T., Kingston, A., Simard, B. Single-walled carbon nanotube-epoxy composites for structural and conductive aerospace adhesives. Composites Part B: Engineering. - 2015. - 69. - P. 87 - 93. https://doi. org/10.1016/j.compositesb.2014.09.022

7. Niu, T. Carbon nanotubes advance next-generation electronics. Nanotoday. - 2020. - 35, 100992. https:// doi.org/10.1016/j.nantod.2020.100992

8. Muñoz, B.K., Bosque, A., Sánchez, M., Utrilla, 
V., Prolongo, S.G., Prolongo, M.G., Ureña, A. Epoxy resin systems modified with ionic liquids and ceramic nanoparticles as structural composites for multifunctional applications. Polymer. - 2020, 123233. https:// doi.org/10.1016/j.polymer.2020.123233

9. Verma, Ch., Olasunkanmi, L.O., Akpan, E.D., Quraishi, M.A., Dagdag, O., El Gouri, M., Sayed, E., Sherif, M., Ebenso, E.E. Epoxy resins as anticorrosive polymeric materials: A review. Polymer. -2020, 104741. https://doi.org/10.1016/j.reactfunctpolym.2020.104741 10. Chen, J., Han, J. Effect of hydroxylated carbon nanotubes on the thermal and electrical properties of derived epoxy composite materials. Results in Physics. 2020. - 18, 103246. https://doi.org/10.1016/j.rinp.2020. 103246

11. Aslan, A., Salur, E., Düzcükoğlu, H., Sinan Şahin, Ö., Ekrem, M. The effects of harsh aging environments on the properties of neat and MWCNT reinforced epoxy resins. Construction and Building Materials. 2021. - 22, 1211929. https://doi.org/10.1016/j.conbuildmat.2020.121929

12. Luo, H., Qiu, J. Carbon nanotubes/epoxy resin metacomposites with adjustable radio-frequency negative permittivity and low dielectric loss. Ceramics International. - 2019. - 45 (1). - P. 843 - 848. https:// doi.org/10.1016/j.ceramint.2018.09.253

13. Roy, D., Tiwari, N., Mukhopadhyay, K., Kumar Saxena, A. The effect of a doubly modified carbon nanotube derivative on the microstructure of epoxy resin. Polymer. - 2014. - 55 (2). - P. 583 - 593. https://doi. org/10.1016/j.polymer.2013.12.012

14. Bui, K., Dimitrios, G., Papavassiliou, V. Heat transfer in high volume fraction CNT nanocomposites:
Effects of inter-nanotube thermal resistance. Chemical Physics Letters. - 2011. - 508 (4-6). - P. 248 - 251. https://doi.org/10.1016/j.cplett.2011.04.005

15. Kharitonov, A.P., Simbirtseva, G.V., Tkachev, A.G., Blohin, A.N., Dyachkova, T.P., Maksimkin, A.A., Chukov, D.I. Reinforcement of epoxy resin composites with fluorinated carbon nanotubes. Composites Science and Technology, - 2015. - 107. - P. 162 - 168. https:// doi.org/10.1016/j.compscitech.2014.12.002

16. https://www.yumpu.com/en/document/view/ 17990242/epoxy-resins-product-overview-the-dowchemical-company

17. https://www.freepatentsonline.com/y2016/0289492 18. Лемеш, Н.В., Лысенков, Э.А., Гомза, Ю.П., Клепко, B.B. $u$ дp. Структура многослойных углеродных нанотрубок, полученных каталитическим разложением этилена на наночастицах никеля. Український хімічний журнал. - 2010. - 76, №5. - С. 29 - 36

19. Корсканов, В.В., Привалко, В.П., Венцель, М., Чжанг, Ч., Алиг, И. Тепло- и электропроводность сшитых эпоксидных смол. - 2004. - Т. 26 (3). C. 167 - 171.

20. Корсканов, В.В. Термодинаміка формування та теплофізичні властивості нанокомпозитів на основі епоксидного полімеру та карбонанотрубок. - 2013. №11. - С. 83 - 89 .

21 . Donth, $E$. The size of cooperatively rearranging regions at the glass transition. Journal of Non-Crystalline Solids. - 1982. - Vol. 53 (3). - P. 325 - 330. https://doi. org/10.1016/0022-3093(82)90089-8

22. Montserrat, S. Effect of crosslinking density on $\mathrm{DC}_{\mathrm{p}}\left(\mathrm{T}_{\mathrm{g}}\right)$ in an epoxy network. Polymer. - 1995. Vol. 36. No. 2. - P. 435 - 436. 